\title{
SiM
}

\section{Stocking Rate Decisions Are Not Related to What You Paid for Your Land or Pickup}

\author{
By W. Marshall Frasier and Tim Steffens
}

\section{On the Ground \\ - We develop a simple bio-economic model to re- flect the stocking rate decision for a profit-seeking land manager and use it to identify factors influenc- ing the optimal stocking rate. \\ - The optimal stocking rate will be bounded by the rate that maximizes average animal performance and that maximizing total animal production per unit of rangeland. \\ - The optimal stocking rate tends closer toward the upper bound as the ratio of the value of the animal product increases relative to the variable costs of production. \\ - Fixed costs or overhead do not influence the optimal stocking rate, but will affect the amount of profit.}

Keywords: bio-economic modeling, optimal stocking rate, stocking rate, economics, overhead costs, fixed costs, variable costs, value of production, gross margin analysis.

Rangelands 35(5):14-21

doi: 10.2111/RANGELANDS-D-13-00027.1

(c) 2013 The Society for Range Management

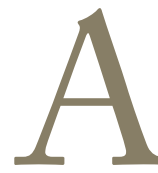

common approach to mitigating the effects of high fixed costs is to increase production activities to "spread" those costs. This strategy is often useful to businesses that are dependent on large amounts of machinery and facilities to add value to raw materials and whose actions to increase production do not limit the supply of those raw materials - that is, they are able to take advantage of slack capacity. However, it is often inappropriate when talking about businesses with a natural resource base of limited carrying capacity, such as grazing operations that depend on biological conversion of forage resources for their income. When animal numbers are so high that the marginal return doesn't cover marginal costs, you can find yourself in a hole that you have dug for yourself. And the first law of holes is this: When you find yourself in one, stop digging.

With a fixed land area, the ability to increase stocking rate profitably is limited by the biological relationship between forage availability and interanimal competition for forage of sufficient quality, ${ }^{1}$ and when stocking rate is wrong, applying all the other grazing management tools only forestalls the inevitable. The following discussion is a variation of the explanation that Hart provided in $1978 .{ }^{2}$ We use information from both Jones and Sandland ${ }^{1}$ and Hart, ${ }^{2}$ though with a slightly different approach, and encourage those wanting to explore the idea in more depth to consult both of these sources. Our approach mathematically analyzes the biological and financial relationships determining the most profitable stocking rate (animal demand per unit of land for a specified period of time), but differs from that of $\mathrm{Hart}^{2}$ in that it first uses information from Jones and Sandland ${ }^{1}$ to show how to determine the stocking rate at which productivity is maximized and then calculates an adjustment factor based on the ratio of variable costs to the value of production for a given piece of property, which we believe simplifies and clarifies the subject for the reader.

In the context of the analytic results, we discuss how the optimum economic stocking rate changes with different environmental and financial conditions, and why overcapitalization, (high fixed costs or overheads) on a limited land base must be dealt with as a problem that is independent of the stocking rate decision. We then provide a quantitative example similar to a small stocker operation on semiarid rangeland to illustrate how changing environmental and economic conditions change the stocking rate at which returns are maximized. We clearly show how fixed costs have no bearing on that stocking rate, but will affect the amount of profit. Our example should also help resource managers evaluate their own situation to identify the range in stocking rates that may be optimal in their own circumstances. 
In order to better understand these relationships, we explain and illustrate terms, beginning with the most basic and increasing in complexity, so that the concepts and principles can be understood by everyone, whatever their background in biology or economics. We provide a quick reference for definitions and symbols in Box 1 to facilitate understanding of these symbols in the formulas and text. We also provide a sidebar (Box 2) that details the mathematical representation of the relationships that generate the principal results that we discuss. Calculus is used to determine how livestock performance, stocking rate, fixed or overhead costs, variable costs, and commodity prices each affect profit. Most of the mathematical manipulations are simple algebra and can be easily understood by the layman. We encourage the reader to follow the referenced equation sidebar when reading the narrative to enhance their understanding of the key relationships. The accompanying explanation and graphical depictions should make the logic clear to those with limited experience with algebra and calculus. The general concepts should be clear simply from the discussion of the resultant figures, but the formulas and derivations are provided to show the precise quantitative relationships that would otherwise not be clearly depicted.

Other articles in this issue of Rangelands discuss the dynamic nature of optimum stocking rate and its connection to other key components of management in ever-changing environments. Many of the relationships and managerial tools described in detail there can be qualitatively translated into the simple parameters utilized here. Following the development of the economic model we show how this tool can be used in the context of these related articles to help managers conceptualize the ultimate impact on optimal stocking rates for a wide range of practical applications.

The explanation we provide here allows a producer familiar with a tract of rangeland to use market information to establish an initial stocking rate that maximizes profitability and provides insights into opportunities for risk management for normal ranges of variability. The discussion that follows formalizes how these general concepts translate a given forage resource and management approach in terms of dollarsa response in which those managing range resources in a market-driven economy should all be interested.

\section{The Relationship Between Stocking Rate and Productivity}

The path to determine the optimal economic stocking rate begins with understanding the biological response under different stocking rates. At low stocking rates, there is little competition between animals; increasing animal numbers doesn't affect individual productivity. But at some point, additional animals will affect the performance of other animals in the pasture and the average performance across all animals begins to decline. The decline in performance after this threshold has been found to be linear over the range of stocking rates commonly seen in commercial operations. ${ }^{3}$

\section{Box 1}

Definitions and Abbreviations (in order of appearance in the text)

$N$ stocking rate; number of animals per given land area (typically 1 acre) for a specified period of time (head/area)

$P_{H} \quad$ units of animal production per animal for a grazing period (weight per head)

$m$ maximum individual animal performance (absence of competition) (weight per head)

$i$ stocking rate threshold where average animal performance begins to decline from $m$ (head/area)

$b$ rate at which average animal performance decreases when $N$ is increased above $i$ ([weight per head]/[head/ area])

$P_{A}$ total animal production per land area under a specified stocking rate (weight/area)

$N_{P_{A} \max }$ stocking rate that generates the maximum total animal production (head/area)

$\pi$ profit generated from land area under a specified stocking rate $(\$ /$ area $)$

$R$ revenue generated from land area under a specified stocking rate (\$/area)

C total costs generated from land area under a specified stocking rate (\$/area)

c variable costs per animal for grazing period (\$ per head)

O overhead (fixed) costs incurred to graze land area for grazing period (\$/area)

$V$ value per unit of animal production (\$/weight per head)

$N_{\pi \_\max }$ stocking rate that generates the greatest total profit to the land area for the grazing period (head/area)

Gross margin value of total production minus total variable costs (\$/area)

Animal performance under these circumstances is represented by the dashed curve $\left(P_{H}\right)$ in Figure 1, which depicts the average animal production as a function of the stocking rate in a specific environment and management regimen. Note that for low stocking rates (less than i) the average productivity per animal is constant. For higher stocking rates the average production per head declines at a constant rate $(b)$ as additional animals are added to the pasture. This relationship is expressed in Equation 1 in the algebraic logic sidebar (Box 2). If average animal per- 


\section{Box 2}

\section{Algebraic Logic for Optimal Stocking Rate}

Case of Linear Decline in Animal Performance and No Long-Run Feedback

Production per animal arising from a given stocking rate:

For $N \leq i: P_{H}=m$

For $N \geq i: P_{H}=m-b(N-i)$

Stocking rate that drives average animal performance to zero (from Equation 1b):

$N=\frac{(m+b i)}{b}$

Total animal production per land area (extending Equation 1):

For $N \leq i: P_{A}=m N$

For $N \geq i: P_{A}=[m-b(N-i)] N=N m-b N^{2}+N b i$

Change in total animal production as stocking rate changes (from Equation $3 b$ ):

$\frac{\partial P_{A}}{\partial N}=m-2 b N+b i$

Stocking rate that achieves maximum total animal productivity (from setting Equation 4 to zero):

$N_{P_{A} \max }=\frac{(m+b i)}{2 b}$

Now, to introduce the economic context...

Revenue from salable total animal product (utilizing Equation $3 b)$ :

$R=V\left(N m-b N^{2}+N b i\right)$

Costs including those that vary with stocking rate and fixed overhead costs:

$\mathrm{C}=\mathrm{cN}+\mathrm{O}$

Profit for a given stocking rate (subtract costs (Equation 7) from revenue (Equation 6)):

$\pi=V N m-V b N^{2}+V N b i-c N-O$

The derivative of Equation 8 with respect to stocking rate shows how profit changes with stocking rate (i.e., the "marginal profit" for any given stocking rate):

$\frac{\partial \pi}{\partial N}=V m-2 V b N+V b i-c$

Solving for the stocking rate that yields the maximum profit (from setting Equation 9 to zero):

$N_{\pi_{-} \max }=\frac{V m+V b i-c}{2 V b}=\frac{(m+b i)}{2 b}-\frac{c}{2 V b}$

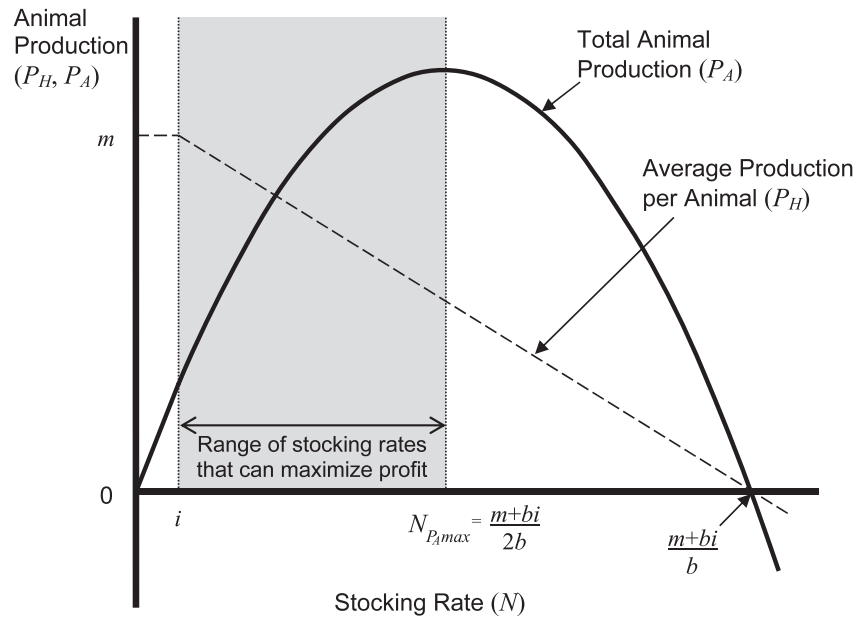

Figure 1. The relationship of production per animal and total production to stocking rate.

Per-animal gains $\left(P_{H}\right)$ decline linearly beyond crowding threshold $i$. Production per unit of land area $\left(P_{A}\right)$ increases until the marginal increase in production contributed by the additional animal is less than the marginal decrease in combined performance all animals resulting from competition for forage resources. Under these circumstances the maximum total production occurs at one half the stocking rate that results in no animal gain. (Note that $P_{A}$ and $P_{H}$ are on different vertical scales.) After Jones and Sandland ${ }^{1}$ and Hart $^{3}$.

formance declines in the fashion described, the stocking rate at which average animal performance will be driven to zero is determined as a function of model parameters (Equation 2).

Given that average animal performance responds to stocking rate as described above, the total production for a given tract of grazing land under a specific stocking rate can be determined. The solid, parabolic curve $\left(P_{A}\right)$ in Figure 1 represents total animal production per unit of land area, which is simply the product of the average animal productivity times the stocking rate (Equation 3).

As depicted in Figure 1, for stocking rates less than $i$ the total animal production per acre of land increases at a constant rate (or linearly) as stocking rate increases. Increasing the number of animals for any stocking rate below $i$ does not affect individual performance because enough high-quality forage is available for all animals to select a diet that allows them to produce at their potential for the environment.

Above the "tipping" stocking rate threshold of $i$, however, average animal production begins to decline. At first, the gain from adding an additional stocked animal more than offsets the decline in the herd average so the total production per acre continues to increase. As stocking rate continues to increase, at some point the increased production contributed by another animal will be less than the total loss in performance of all the animals as a result of that animal's competition for resources, thereby decreasing total production for the area being managed (the peak of solid production curve $\left[P_{A}\right]$, Fig. 1).

Armed with this information alone, we can identify a range of stocking rates that make economic sense even with- 
out any price or cost information. First, there is no incentive to stock at a rate lower than $i$. If the gain per animal unit without a crowding effect is desirable at any stocking rate less than $i$, then adding additional animals that would gain the same amount would be more desirable. Adding additional animals past the point $i$ adds a positive, but decreasing increment to total productivity up to the point where $P_{A}$ is maximized. Increasing stocking rate beyond this point is counterproductive as the manager will clearly generate less total productivity as more animals are stocked. Therefore, the optimum stocking rate will always be somewhere between these two levels (shaded area in Fig. 1).

Looking only at the graph, it is difficult to precisely determine at exactly what stocking rate total production is maximized. Using calculus to determine the first derivative of the total animal production per acre with respect to stocking rate we are able to specify an equation that describes how much $P_{A}$ changes as we change $N$ for any given stocking rate (Equation 4). This equation can be interpreted as the "marginal productivity of stocking rate." Using this relationship, we can identify the stocking rate where total productivity is maximized (i.e., where marginal productivity is zero) by solving for the $N$ that satisfies this (Equation 5).

The result of our manipulation of the algebraic model yields an explicit relationship that demonstrates that if average animal performance declines linearly in stocking rate as outlined above, the stocking rate at which total animal production per acre is maximized (Equation 5) will be halfway between a stocking rate of zero and that at which average animal production (gain) is driven to zero (Equation 2). This can also be seen in the graph of total animal production in Figure 1 where the peak of the curve appears at that midpoint. Given that fact, to determine the stocking rate at which total production is maximized, all that is needed is the individual performance at a given stocking rate and the incremental change in average animal performance with an incremental change in stocking rate (i.e., the slope of the line). With those two values, the stocking rate at which gain would be driven to zero can be calculated. A stocking rate of one-half of that rate would be the point of maximum production for the area.

\section{Economic Relationships}

Generally, managers should be more concerned with profits than production (though the two are clearly related). And in a market-driven system, nothing comes free. By definition, the profit for a given enterprise is simply the difference between total revenue and total costs. In circumstances in which the value per unit of production is constant, revenue is given simply as the product of the value per unit of production and the total amount of production. We established earlier that total animal production for a given land area was driven by stocking rate and that only stocking rates above the crowding threshold would be relevant (Equation 3b), so we can use those facts to determine the relationship between

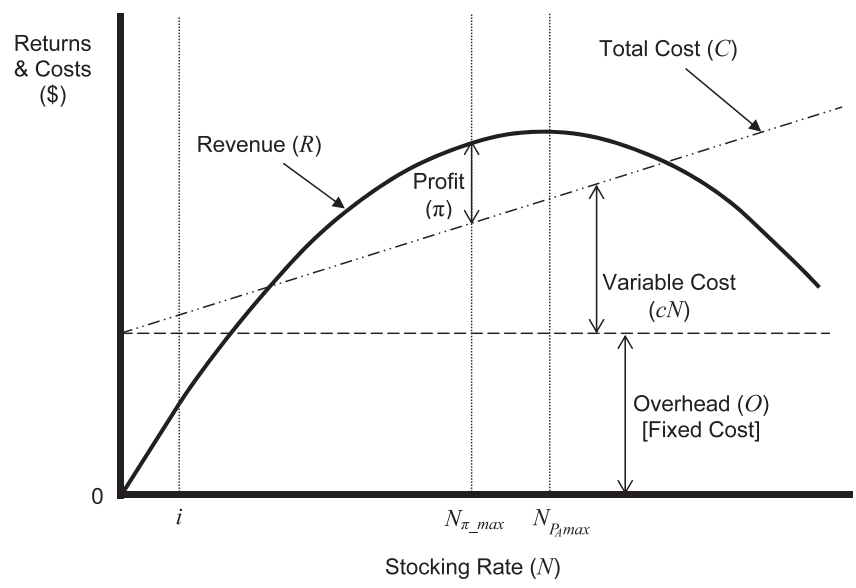

Figure 2. Relationship among revenue, cost, and stocking rate in a grazing enterprise.

Revenue is driven by production per unit of land area $\left(P_{A}\right)$ and is maximized at the stocking rate that maximizes total animal production per acre. Costs increase linearly in stocking rate, resulting in the profit-maximizing stocking rate being less than (to the left of) the stocking rate that maximizes animal production per acre. Shifts in overhead or fixed cost will affect the magnitude of profit, but not the optimal stocking rate.

stocking rate and total revenue per acre of land (Equation 6). As seen in Figure 2, the graph of this relationship takes the same shape as did that of the total animal production relationship in Figure 1.

Costs can be characterized as either overhead (fixed costs) or variable costs. Overhead costs are those that do not change significantly over wide ranges in production, and are generally associated with fixed resources of production that, depending on circumstances, can include land, equipment, capital improvements, and sometimes labor. Variable costs change with each incremental increase in units of production activity and may include factors such as feed, marketing expenses, interest on operating capital, etc. When considering the decision of selecting the stocking rate for a given grazing enterprise, total costs can be expressed as the sum of those costs that vary directly with the number of animals (aka, "carrying costs") and the overhead costs. Equation 7 represents this relationship and it is apparent graphically in Figure 2 as the stacking of the variable cost "wedge" on top of the overhead costs, which do not change with the stocking rate. Now the profit associated with any given stocking rate can be seen as the vertical distance between the revenue curve $(R)$ and the total cost curve $(C)$, being at its maximum where labeled on the graph. Where revenue lies above the total cost curve, profits per acre of grazing land are positive; for stocking rates where total cost lies above revenue, profits are negative.

Up to this point the algebra has not been necessary to support the arguments provided (in fact, the logical arguments have been provided primarily to justify the mathematical representations). Now, however, we exploit the mathematical model to demonstrate what simple intuition alone would not reveal. With the explicit relationships for revenue and costs detailed, simply taking their difference yields the equa- 
tion that expresses the profit per acre of land as a function of stocking rate (Equation 8). Employing calculus, we can find how profit changes with stocking rate (i.e., the "marginal profit" for any given stocking rate) which is given by Equation 9. To find the stocking rate that will maximize profit to a given tract of land, we find the point at which profit does not change as the last animal is added or removed. Solving for the stocking rate that maximizes profits yields the principal result of the model that allows us to evaluate the factors that will determine the optimal stocking rate for the circumstances described (Equation 10).

Close inspection of Equation 10 reveals that the optimal economic stocking rate depends only on the value per unit of animal production $(V)$, variable cost per animal $(c)$, and the animal response parameters $(m, b$, and $i)$. Note that overhead has dropped out of the equation. Regardless of how much money is invested in land, long-term labor, or equipment, or how those resources are financed (all overhead costs), the most desired stocking rate is unaffected. Certainly those costs affect the profitability of the enterprise (see Equation 8), but if they are too high for the operation to be profitable when the value of total production minus total variable costs (total gross margin) is maximized, increasing stocking rate further would decrease, rather than increase, profit because a lower gross margin leaves less to be applied to fixed overhead costs (Fig. 2).

Another advantage of the algebraic expression in Equation 10 is that the first term is identical to Equation 5, which identified the stocking rate that maximizes total animal production. Because none of the parameters in the second term $(c, V, b)$ can take negative values, the second term must itself be nonnegative. Hence, the profit-maximizing stocking rate will never exceed the stocking rate that maximizes total animal production- a common result in production economics.

Typical for a wide range of agricultural production problems, the relative prices paid for variable inputs and received for outputs influences the optimal input level (stocking rate) as the variable costs and value of production are weighed against each other in the last term. An increase in the value per unit of production and/or a decrease in variable costs will increase the level of the optimal stocking rate, approaching the rate that maximizes animal production per acre as the second term approaches zero. Conversely, as variable costs increase and/or value of production decreases, the optimal stocking rate is reduced. The rationale for this result is that if a producer faces an increase in variable costs per animal, it will require a decreased stocking rate to improve per-animal performance to recover those higher costs. If both variable costs and value of production change in the same direction, the net effect will be driven by the component with the greatest proportionate change. If both factors shift by the same proportion, optimal stocking rate does not change.

All three of the biological parameters $(m, i, b)$ also play into the determination of optimal stocking rate. As one would expect, and the mathematical analysis bears out, optimal stock- ing rate is directly related to $m$ and $i$, increasing as either increases, but is inversely related to $b$. Even though this model is based on a very simple representation of the plant-animal interaction, many different circumstances can be compared if the key differences can be described in terms of $m, i$, and $b$. This could include, for instance, a shift in climate, plant community changes, or selecting different species, classes, or genetic lines of livestock. It is likely to be difficult to accurately quantify the parameter values, but qualitative changes (increases, decreases, or stability) should be discernible.

Authors of articles that appear in this issue of Rangelands discuss how management adapts to changes in realities that could be represented in terms of $m, b$, and $i$. For instance, by improving distribution of livestock so that they access a greater proportion of the herbage on the landscape on temporal scales that allow them to mix relatively higher-quality forages with lower-quality ones (see Norton et al. and Barnes and Howell, this issue) a manager is essentially striving to increase $m$ and $i$, which would increase the optimum stocking rate. By manipulating the variety of plants available and the rate of disappearance of the higher-quality components, we encourage them to learn how to use new combinations of foods (see Peterson et al., this issue), which can maintain performance with higher numbers of animals (decrease b). Adjusting stocking rate based on forage quantity and quality available when the forage resource has been compromised (see Ortega et al. and Grissom and Steffens, this issue) favorably influences nutrient intake (increases $m$ and $i$, decreases $b$ ) and allows plant communities to recover, thereby improving potential future productivity. Finally, by providing for moderate average use during a grazing period (see Ortega et al. and Grissom and Steffens, this issue) with adequate recovery and establishment opportunities for preferred, often rare, plants following defoliation (see Ortega et al., Grissom and Steffens, Norton et al., Steffens et al., and Peterson et al., this issue) the proportion and productivity of previously overused high quality plants in preferred areas, and possibly the quality and water use efficiency of soils (see discussion in Norton et al., this issue) can be improved in such a way as to increase the maximum sustainable productivity and availability of higher-quality plants on the landscape. All of these can be reflected through improvements in $m, b$, and $i$.

\section{A Practical Example}

The previous discussion describes the generalized bio-economic relationships for the simplified class of circumstances described. The following is a specific example in an environment similar to that described by Hart ${ }^{3}$ that is representative of a small yearling beef cattle operation on semiarid rangeland. In terms of the six parameters for our mathematical model, the base scenario is this:

- Maximum seasonal individual gain $(m)$ of 360 pounds until stocked at 0.0625 animals per acre (i)

- Each additional animal per acre lowers average individual seasonal performance by 960 pounds for each animal on 
Table 1. Summary of stocking rate choices to maximize production and maximize profit over a range of related scenarios

\begin{tabular}{|c|c|c|c|c|c|c|}
\hline & \multirow[b]{2}{*}{$\begin{array}{c}\text { Base } \\
\text { scenario* }\end{array}$} & \multicolumn{5}{|c|}{ Changing parameter values by one-third of original value } \\
\hline & & $\begin{array}{l}\text { 1) Increase } \\
\text { crowding } \\
\text { penalty }(b)^{\dagger}\end{array}$ & $\begin{array}{l}\text { 2) Increase } \\
\text { overhead } \\
(0)^{\ddagger}\end{array}$ & $\begin{array}{c}\text { 3) Increase } \\
\text { variable cost } \\
(c)^{\S}\end{array}$ & $\begin{array}{l}\text { 4) Increase } \\
\text { value of } \\
\text { production } \\
(V)^{\|}\end{array}$ & $\begin{array}{l}5) \text { Increase } \\
\text { variable costs } \\
\text { (c) and value } \\
\text { of production } \\
\text { (V) }\end{array}$ \\
\hline \multicolumn{7}{|l|}{ Maximum production } \\
\hline $\begin{array}{l}\text { Stocking rate } \\
\text { (head per acre) }\end{array}$ & 0.219 & 0.172 & 0.219 & 0.219 & 0.219 & 0.219 \\
\hline $\begin{array}{l}\text { Total gain } \\
\text { (pounds per } \\
\text { acre) }\end{array}$ & 45.9 & 37.8 & 45.9 & 45.9 & 45.9 & 45.9 \\
\hline $\begin{array}{l}\text { Gross margin } \\
\text { (\$ per acre) }\end{array}$ & 12.58 & 11.17 & 12.58 & 5.29 & 24.06 & 16.77 \\
\hline $\begin{array}{l}\text { Profit } \\
\text { (\$ per acre) }\end{array}$ & 1.64 & 0.23 & -2.01 & -5.65 & 13.13 & 5.83 \\
\hline \multicolumn{7}{|l|}{ Maximum profit } \\
\hline $\begin{array}{l}\text { Stocking rate } \\
\text { (head per acre) }\end{array}$ & 0.149 & 0.120 & 0.149 & 0.126 & 0.167 & 0.149 \\
\hline $\begin{array}{l}\text { Total gain } \\
\text { (pounds per } \\
\text { acre) }\end{array}$ & 41.3 & 34.3 & 41.3 & 37.7 & 43.3 & 41.3 \\
\hline $\begin{array}{l}\text { Gross margin } \\
\text { (\$ per acre) }\end{array}$ & 16.05 & 13.78 & 16.05 & 11.46 & 26.67 & 21.40 \\
\hline $\begin{array}{l}\text { Profit } \\
\text { (\$ per acre) }\end{array}$ & 5.11 & 2.84 & 1.47 & 0.52 & 15.73 & 10.46 \\
\hline $\begin{array}{l}\text { *Value of productio } \\
\text { animal seasonal } \\
\text { stocking rate pena } \\
\text { † Same as base sce } \\
\text { ₹Same as base sce } \\
\text { "Same as base sce } \\
\text { "Same as base Sce } \\
\text { "Same as base sce }\end{array}$ & $\begin{array}{l}\text { o }=\$ 0.75 \text { per } \\
m)=360 \text { pou } \\
b)=960 \text { pou } \\
\text { o except stoc } \\
\text { o except over } \\
\text { o except varia } \\
\text { io except valu } \\
\text { io except value }\end{array}$ & $\begin{array}{l}\text { und, variable co } \\
\mathrm{s} \text {, stocking rate } \\
\text { per head per e } \\
\text { g rate penalty }(b \\
\text { d }(O)=\$ 14.58 \\
\text { cost }(c)=\$ 13 \\
\text { f production }(V) \\
\text { p production }(V)\end{array}$ & $\begin{array}{l}(c)=\$ 100 \text { pe } \\
\text { eshold where } \\
\text { a head per acr } \\
=960 \text { pounds } \\
\text { er acre. } \\
33 \text { per head. } \\
\$ 1.00 \text { per por } \\
\$ 1.00 \text { per pou }\end{array}$ & $\begin{array}{l}\text { head, overhead } \\
\text { ins begin to decl }\end{array}$ & $\begin{array}{l}=\$ 10.9375 p \epsilon \\
(i)=0.0625 \vdash \\
\text { ad per acre. }\end{array}$ & $\begin{array}{l}\text { acre, maximum } \\
\text { d per acre, }\end{array}$ \\
\hline
\end{tabular}


the management unit (b) [equivalently: one additional animal per 160 acres will result in a 6 pound reduction in seasonal per-animal performance]

- Value of gain $(V)=\$ 0.75$ per pound

- Variable costs $(c)=\$ 100$ per head

- Fixed costs $(O)=\$ 10.94$ per acre for the grazing season

Table 1 summarizes the outcomes associated with this base scenario and for five selected alternatives. For the base scenario, or Scenario 1, the maximum production possible would be 45.9 pounds per acre when stocking 0.219 animals/ acre. This generates a return above variable costs of $\$ 12.58$ / acre and a return above total costs of $\$ 1.64 /$ acre. By reducing the stocking rate by roughly a third to 0.149 animals/ acre, total gain is reduced to 41.3 pounds per acre, but both returns above variable cost and total profit are increased by $\$ 3.47 /$ acre to maximums of $\$ 16.05$ and $\$ 5.11$, respectively. Reducing stocking rate reduces variable costs by a third while sacrificing only about $10 \%$ of revenue.

When the crowding penalty is increased by one-third (i.e., the $b$ parameter is increased to 8 so that the slope of the $P_{H}$ curve is steeper) as might occur during drought, the total animal production will be lower for all stocking rates. The maximum total gain now occurs at 0.172 head per acre yielding 37.8 pounds per acre of gain. The profit-maximizing stocking rate falls proportionately less to 0.120 head per acre with profits falling to $\$ 2.84$ acre. In landscapes where highquality forage is relatively rare and the difference in quality among plants is relatively high, curves implied in this case will be the norm.

As the productivity of the range shifts, one would expect different results as demonstrated above. Similar qualitative results could be generated for combined changes in the three productivity parameters $(b, i$, and $m)$. Changes in the cost and returns structure will also affect the profitability of the grazing enterprise, though in different ways. The remaining scenarios (Scenarios 2-5) address these adjustments. Across these scenarios the maximum production and the associated stocking rate are not different from the base scenario, but the associated net returns do vary (Table 1). Discussion will focus on changes in the optimal grazing strategy in the face of these adjustments.

In Scenario 2, overhead increases by a third, from $\$ 10.94$ per acre to $\$ 14.58$ per acre. This has no effect on the stocking decision, yielding the same optimal stocking rate, total gain per acre, and gross margin per acre as the base scenario. It does reduce the profit by exactly the $\$ 3.64$ increase in total costs. In fact, any change in overhead or fixed costs will not affect the most profitable stocking rate, though they will affect the fact and the magnitude of that profit. Referring to Figure 2, the shapes of the revenue curve and the total cost curve do not change as overhead changes, only the vertical distance between them. The stocking rate with the greatest positive return is the same, regardless of the level of overhead. In the long run, a producer who faces fixed costs that are in excess of the maximum gross margin attainable will be forced to find ways to reduce the fixed costs, exit, or subsidize the enterprise

When variable costs increase by one-third (Scenario 3), the most profitable stocking rate and the maximum profit decrease to 0.126 head per acre and $\$ 0.52$ per acre, respectively. When the value of production increases by a similar proportional amount (Scenario 4), the most profitable stocking rate and the maximum profit decrease to 0.167 head per acre and $\$ 15.73$ per acre, respectively. When both variable costs and value of production increase by one-third (Scenario 5), the most profitable stocking rate remains constant, but profit (\$10.46 per acre) is higher than in the base scenario. Once again, these results demonstrate that the optimal stocking rate is driven by the ratio of variable costs to value of production.

\section{Conclusions}

An incomplete understanding of the biological and economic relationships regarding stocking rate, range and animal productivity, and cost structure can result in incorrect stocking rate decisions that cause financial losses and resource degradation. The simple model we present here provides insight into the interrelationship of these variables and their influence on optimal stocking rate.

The principal result of the model is that optimal stocking rate will be bounded by the stocking rates that generate the maximum average animal performance and the maximum production per unit land area. As long as there are variable costs in stocking animals, optimal stocking rate will be lower than that which maximizes production to the land unit. Overhead costs, while affecting total profit, do not influence optimal stocking rate.

All models are abstractions from reality and ignore elements that may be important. The two most notable limitations of this simple model are that it does not account for ecological outcomes (the only objective was profit from salable animal production) nor does it account for the long-run dynamics where stocking rate decisions today can influence future productivity of the rangeland resource. In settings where these elements are important, outcomes of the simple model must be qualified. Where grazing intensity negatively influences either desired ecological outcomes or future productivity, optimal stocking rates will be less than the simple model suggests. In many cases, an understanding of the "unaccounted" consequences facilitates the development of models that explicitly account for these added dimensions, which are useful to answer the next round of questions regarding the broader context.

Clearly there are many factors that should determine stocking rate decisions and a six-parameter, single-period model will not provide prescriptive solutions to these complex problems. However, while fully recognizing these limitations, the power of this model lies in its simplicity. The qualitative results are generalizable for a wide range of circumstances and provide the land manager a conceptual framework to account 
for the interactions and tradeoffs between relevant economic and biological realities.

\section{References}

1. Jones, R. J., and R. L. Sandland. 1974. The relation between animal gain and stocking rate. Journal of Agricultural Science (Cambridge) 83:335-342.

2. Hart, R. H. 1978. Stocking rate theory and its application to grazing on rangelands. In: D. N. Hyder [ED.]. Proceedings of the 1st International Rangeland Congress; 14-18 August 1978; Denver, CO, USA. Littleton, CO, USA: Society for Range Management. p. 547-550.
3. Hart, R. H. 1986. How important are stocking rates in grazing management? In: P. E. Reece and J. T. Nichols [EDs.]. Proceedings, The Ranch Management Symposium; 5-7 November 1986; Lincoln, NE, USA. Lincoln, NE, USA: University of Nebraska Agricultural Extension Service. p. 77-87.

Authors are Professor of Agricultural and Resource Economics, Colorado State University, Fort Collins, CO 80523, USA, Marshall. Frasier@ColoState.Edu (Frasier); and Assistant Professor, Dept of Agricultural Sciences, West Texas AEऽM University, Canyon, TX 79016, USA (Steffens). 